\title{
Short communication: Dietary conjugated linoleic acid down-regulates fatty acid transporters in the mammary glands of lactating rats
}

\author{
A. Gutgesell, R. Ringseis, ${ }^{1}$ and K. Eder \\ Institut für Agrar-und Ernährungswissenschaften, Martin-Luther-Universität Halle-Wittenberg, Von-Danckelmann-Platz 2, \\ D-06120 Halle (Saale), Germany
}

\begin{abstract}
Recent studies indicated that reduction of milk triacylglycerol concentrations by dietary conjugated linoleic acid (CLA) involves an impairment of both de novo fatty acid synthesis and uptake of fatty acids from circulating triacylglycerol-rich lipoproteins into the mammary gland. However, nonesterified fatty acids (NEFA) in the plasma released from adipose tissue and taken up into the mammary gland by fatty acid transporters are a further important source of fatty acids available for milk triacylglycerol synthesis. Therefore, the aim of the present study was to investigate the effect of dietary CLA on plasma concentrations of NEFA and the expression of fatty acid transporters in the mammary glands of lactating rats fed either a CLA diet or a control diet. Dams fed diets with CLA had a greater concentration of NEFA in plasma than those fed the control diet. In addition, relative mRNA concentrations of fatty acid transporters (fatty acid translocase/CD36, fatty acid transport protein, and plasma membrane fatty acid binding protein) were about 45,75 , and $70 \%$ lower, respectively, in the mammary gland of dams fed diets with CLA compared with those fed the control diet. In conclusion, the present findings indicate that reduced uptake of circulating NEFA released from white adipose tissue into the mammary gland could also contribute to the reduction of milk triacylglycerol concentrations by dietary CLA in rats. The mechanism through which CLA inhibits expression of fatty acid transporters deserves further study.
\end{abstract}

Key words: conjugated linoleic acid, fatty acid transporters, lactation, mammary gland

Conjugated linoleic acid (CLA) is a collective term for a group of positional and geometric isomers of linoleic acid with conjugated double bonds. Conjugated linoleic acid is naturally found in significant amounts in milk, dairy products, and meat of ruminants (Steinhart

Received August 18, 2008

Accepted October 29, 2008.

${ }^{1}$ Corresponding author: robert.ringseis@landw.uni-halle.de et al., 2003). Several studies showed that dietary CLA exerts many biological effects in humans and animals (Martin et al., 2000; Baumgard et al., 2001; Masters et al., 2002; Terpstra et al., 2002; Toomey et al., 2006). For instance, in lactating rats (Ringseis et al., 2004; Hayashi et al., 2007), sheep (Lock et al., 2006), cows (Baumgard et al., 2001, 2002; Peterson et al., 2004; Harvatine and Bauman, 2006), and humans (Masters et al., 2002) dietary CLA causes a reduction in milk triacylglycerol concentration.

Milk triacylglycerol synthesis depends on the availability of fatty acids in the mammary gland, which are derived from 3 different sources. The first source represents de novo biosynthesis of fatty acids within the mammary gland by the activity of lipogenic enzymes. Medium-chain fatty acids with 8 to 14 carbon atoms are the main products of this process, which is controlled by the lipogenic transcription factor sterol regulatory element-binding protein (SREBP)-1c (Barber et al., 2003). Fatty acids released from triacylglycerol-rich lipoproteins by lipoprotein lipase and taken up into the mammary gland by fatty acid transporters are a second important source for milk triacylglycerol synthesis (Scow et al., 1977). Nonesterified fatty acids in the plasma released from adipose tissue by hormone-sensitive lipase and taken up into the mammary gland by fatty acid transporters are a third source of fatty acids available for milk triacylglycerol synthesis. Fatty acids with 16 carbon atoms and long-chain fatty acids with 18 to 22 carbon atoms, either saturated or unsaturated, largely reflect the second and third sources of fatty acids for milk triacylglycerol synthesis (Green et al., 1981; Ross et al., 1985). The contribution of NEFA to milk fat synthesis in lactating cows is especially important during the early lactation stage, because the capacity for feed intake is limited at the beginning of lactation and therefore adipose tissue depots, which have accumulated during pregnancy, are actively mobilized during this stage. In mid and late lactation NEFA are of minor importance for milk fat synthesis in dairy cows because feed intake is sufficient to provide enough substrates for milk fat synthesis and even to replenish lipid stores during this lactation stage. In contrast, NEFA 
are an important source for milk fat synthesis during the whole lactation in species with a high milk yield such as the rat, whose demand for lactation is so large that food intake is dramatically increased (up to 3- to 4-fold compared with nonlactating rats; Peterson and Baumgardt, 1971). In spite of the large increase in feed consumption, however, rats are generally in negative energy balance during lactation, in particular during peak lactation (d 12 to 14 postpartum), where mobilization of body fat and protein is greatest (Sampson and Janson, 1984). Consequently, rats usually lose weight during lactation regardless of the feeding regimen (e.g., ad libitum) or the energy content of the diet (Sainz et al., 1986).

Several studies have shown that the reduced milk triacylglycerol concentrations by dietary CLA were accompanied by a diminished activation of SREBP-1c and reduced expression and activity of lipogenic enzymes and lipoprotein lipase in the mammary gland (Baumgard et al., 2002; Peterson et al., 2004; Ringseis et al., 2004; Harvatine and Bauman, 2006). These findings clearly indicate that dietary CLA reduces milk triacylglycerol concentrations by impairment of both de novo fatty acid synthesis and uptake of fatty acids from circulating triacylglycerol-rich lipoproteins into the mammary gland. However, whether the reduced concentrations of long-chain fatty acids and triacylglycerols in the milk by dietary CLA are also the consequence of diminished uptake of NEFA by fatty acid transporters from plasma into the lactating mammary gland has not been investigated yet. Therefore, the aim of the present study was to investigate the effect of dietary CLA on plasma concentrations of NEFA and the expression of the most important fatty acid transporters, fatty acid translocase/CD36 (FAT/CD36), fatty acid transport protein (FATP), and plasma membrane fatty acid binding protein (FABPpm), in the mammary gland of lactating rats. For this purpose, we used samples of a recently performed feeding experiment with lactating rats that were fed either a CLA diet or a control diet containing sunflower oil (SFO; Ringseis et al., 2004). In this experiment, the rats of the CLA group had a $46 \%$ lower milk fat content and markedly lower absolute concentrations of medium-chain fatty acids, fatty acids with 16 carbon atoms, and long-chain fatty acids in the milk at d 10 postpartum [C8 to C14: CLA group: $56 \pm$ $13 \mathrm{mmol} / \mathrm{L}, \mathrm{n}=8, \mathrm{SFO}$ group: $149 \pm 6 \mathrm{mmol} / \mathrm{L}, \mathrm{n}=$ 10, means \pm SEM, $P<0.05$; C16: CLA group: $47 \pm 9$ $\mathrm{mmol} / \mathrm{L}, \mathrm{n}=8$, SFO group: $85 \pm 4 \mathrm{mmol} / \mathrm{L}, \mathrm{n}=10$, means \pm SEM, $P<0.05$; C18 to C22: CLA group: 99 $\pm 17 \mathrm{mmol} / \mathrm{L}, \mathrm{n}=8$, SFO group: $140 \pm 8 \mathrm{mmol} / \mathrm{L}, \mathrm{n}$ $=10$, means \pm SEM, $P<0.05$, (Ringseis et al., 2004)]. Relative proportions of medium-chain fatty acids in the milk were also lower in the CLA group than in the SFO group (CLA group: $17.6 \pm 1.6 \mathrm{~g} / 100 \mathrm{~g}$ of fatty acids, $\mathrm{n}$ $=8$, SFO group: $28.5 \pm 2.2 \mathrm{~g} / 100 \mathrm{~g}$ of fatty acids, $\mathrm{n}=$ 10 , means \pm SEM, $P<0.05$ ), whereas proportions of C16:0 and long-chain fatty acids did not significantly differ between the groups (C16:0: CLA group: $23.6 \pm$ $0.5 \mathrm{~g} / 100 \mathrm{~g}$ of fatty acids, $\mathrm{n}=8$, SFO group: $22.8 \pm 0.8$ $\mathrm{g} / 100 \mathrm{~g}$ of fatty acids, $\mathrm{n}=10$, means $\pm \mathrm{SEM}$; C18 to C22: CLA group: $49.0 \pm 3.2 \mathrm{~g} / 100 \mathrm{~g}$ of fatty acids, $\mathrm{n}$ $=8$, SFO group: $41.2 \pm 1.5 \mathrm{~g} / 100 \mathrm{~g}$ of fatty acids, $\mathrm{n}=$ 10 , means \pm SEM). The rats, at a mean BW of $64 \pm 1$ $\mathrm{g}$ (mean \pm SEM), were randomly assigned to 2 groups $(\mathrm{n}=12)$ and fed the diets with $30 \mathrm{~g} / \mathrm{kg}$ diet of either sunflower oil (SFO group) or CLA oil (CLA group). The fatty acid compositions of total lipids of SFO and the CLA oil were similar except for the concentrations of 18:2 n-6 and CLA. The CLA oil contained $54 \mathrm{~g}$ of CLA isomers/100 g of CLA oil, whereas the CLA concentration in the SFO was $<0.1 \mathrm{~g}$ per $100 \mathrm{~g}$ of total fatty acids. The CLA isomer distribution of the CLA oil was as follows $(\mathrm{g} / 100 \mathrm{~g}$ of total CLA): trans $(\boldsymbol{t})$ 10 cis (c)-12 (18.5), c11t13 (15.8), c9t11 (15.6), t8c10 (14.9), t10t12 (5.61), t9t11 (5.41), t7t9 (3.12), c13t15 and $t 13 c 15$ (2.85), $t 11 t 13$ (2.75), t8t10 (2.63), $c 10 c 12$ (2.58), $t 12 t 14$ (2.22), $c 9 c 11$ (2.08), $c 11 c 13$ (1.99), $c 8 c 9$ (1.30), $c 12 t 13$ and $t 12 c 13(0.97), t 7 c 9$ (0.79), t11c13 $(0.62), t 6 t 8(0.18)$, and $t 13 t 15(0.13)$. At 11 wk of age, the rats were paired with adult male Sprague-Dawley rats for $6 \mathrm{~d}$. At the day of parturition, designated as d 1 of lactation, litters were weighed and then adjusted to 10 pups per dam without differentiation of sex. The experimental diets were fed for a total of $13 \mathrm{wk}$, starting at 5 wk of age. During growth and pregnancy, the rats were fed identical amounts of the experimental diets, increasing from 7 to $19 \mathrm{~g} / \mathrm{d}$, except for wk 11. In wk 11, when the rats were paired with the male rats, they had free access to the experimental diets. Throughout the period of lactation, the rats also had free access to the experimental diets; however, daily food intake during lactation did not differ between groups [CLA group: $33.7 \pm 1.4 \mathrm{~g} / \mathrm{d}, \mathrm{n}=8$; SFO group: $34.9 \pm 0.9 \mathrm{~g} / \mathrm{d}, \mathrm{n}=$ 10 , means \pm SEM (Ringseis et al., 2004)]. Based on an energy content of the diets of $17.5 \mathrm{MJ} / \mathrm{kg}$ of diet, the daily food intake during lactation was $590 \pm 25 \mathrm{~kJ} / \mathrm{d}$ in the CLA group $(\mathrm{n}=8)$ and $611 \pm 16 \mathrm{~kJ} / \mathrm{d}$ in the SFO group $(\mathrm{n}=10)$, means \pm SEM. Plasma and samples of mammary gland were obtained on d 17 of lactation, when the dams were anesthetized with diethyl ether and killed by decapitation. Day 17 of lactation in rats corresponds to the late lactation stage where milk yield is slowly declining because pups suckle less milk. During these final days of lactation, the energy and nutrient demands of the pups are partially met by the consumption of solid food. Further details regarding animals, diets, feeding regimen, and sample collec- 

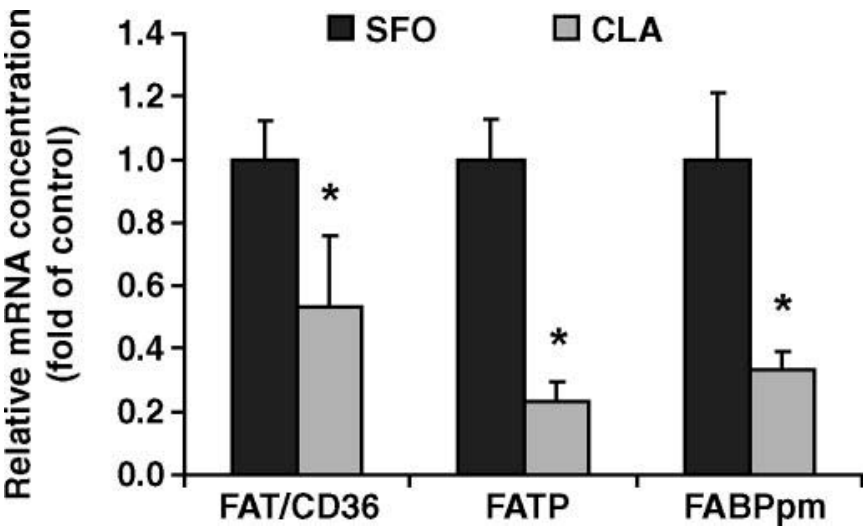

Figure 1. Relative mRNA concentrations of fatty acid transporters, fatty acid translocase/CD36 (FAT/CD36), fatty acid transport protein (FATP), and plasma membrane fatty acid binding protein (FABPpm), in the mammary gland of lactating rats fed diets with either conjugated linoleic acid (CLA) or sunflower oil (SFO). Bars represent mean \pm SEM for $n=10$ (SFO) and $n=8$ (CLA) rats, respectively, and are expressed as fold changes of relative mRNA concentration in CLA group compared with the SFO group. *Different from rats fed diets with SFO, $P<0.05$.

tion can be found in our recent article (Ringseis et al., 2004). Plasma NEFA concentrations were determined using the enzymatic NEFA C kit from Wako Chemicals (Neuss, Germany, Ref. 99975406). For the determination of mRNA expression levels of FAT/CD36, FATP, FABPpm, and GAPDH as internal standard for normalization, total RNA was isolated from mammary glands using TrizolP reagent (Invitrogen, Karlsruhe, Germany) according to the manufacturer's protocol. Glyceraldehyde-3-phosphate dehydrogenase served as an appropriate reference gene in this experiment because the cycle threshold (CT) values of GAPDH did not differ between treatment groups. Concentration and purity of RNA were estimated from the optical density at 260 and $280 \mathrm{~nm}$, respectively. Synthesis of cDNA and relative quantification of target-gene mRNA compared with housekeeping-gene mRNA was determined by real-time detection PCR as described previously (Ringseis et al., 2007). Relative expression ratios are expressed as fold changes of mRNA abundance in the CLA group compared with the SFO group. Sequences of gene-specific primers obtained from Operon (Köln, Germany) were as recently published (Ringseis et al., 2007). Treatment effects were analyzed using one-way ANOVA. For significant $F$-values, means were compared by Fisher's multiple range test. Differences with $P<0.05$ were considered significant.

Figure 1 shows the effect of treatment on relative mRNA concentrations of fatty acid transporters in the mammary gland. Relative mRNA concentrations of FAT/CD36, FATP, and FABPpm were about 45, 75, and $70 \%$ lower, respectively, in the mammary glands of dams fed diets with CLA than in those fed diets with SFO $(P<0.05)$. Analysis of NEFA concentrations in plasma revealed that dams fed diets with CLA had a greater concentration of NEFA in plasma than those fed diets with SFO (CLA group: $440 \pm 34 \mu \mathrm{Eq} / \mathrm{L}, \mathrm{n}=$ 8, SFO group: $330 \pm 10 \mu \mathrm{Eq} / \mathrm{L}, \mathrm{n}=10$, means $\pm \mathrm{SEM}$, $P<0.05)$.

The present study shows for the first time that fatty acid transporters, which mediate cellular uptake of albumin-bound NEFA originating from hydrolysis of triacylglycerols by hormone-sensitive lipase in white adipose tissue and subsequent release into the circulation, are markedly down-regulated, as evidenced by decreased transcript levels in the mammary glands of dams fed CLA. Although down-regulation of fatty acid transporters was not proven on the protein level, we suggest that the transport capacity of the mammary gland for circulating NEFA is probably impaired in lactating rats by dietary treatment with CLA. Indeed, the finding that plasma NEFA concentrations were significantly greater in dams fed the CLA diet than in those fed the control diet is supportive of this assumption. Nevertheless, this finding in rats is in contrast to the observation in dairy cows that plasma NEFA levels are not altered by treatment with CLA (Perfield et al., 2002). Although we cannot explain this discrepancy, we are confident that the increased plasma NEFA concentrations in the CLA group are not the result of a decreased energy intake leading to an increased release of NEFA from adipose tissue and, subsequently, a reduced BW. This assumption is based on the finding that feed and energy intake as well as BW development during lactation did not differ between rats of the CLA and SFO groups (Ringseis et al., 2004). In connection with our recent observations that the concentrations of fatty acids with 16 carbon atoms and long-chain fatty acids with 18 to 22 carbon atoms in the milk, which originate both from the diet and white adipose tissue, were reduced by dietary CLA, we suggest that dietary CLA impairs the uptake of those fatty acids into the mammary gland. This may contribute to a reduced availability of fatty acids in the mammary gland, which in turn leads to a reduced milk triacylglycerol synthesis.

The CLA oil used in the present study contained a large number of CLA isomers. Among them, $t 10 c 12$ CLA, $c 11 t 13-C L A, c 9 t 11-C L A$, and t8c10-CLA were the major CLA contributing to about $65 \mathrm{~g} / 100 \mathrm{~g}$ of total CLA. The remaining CLA identified consisted of minor isomers in trans/cis-, cis/trans-, trans/trans-, and cis/cis-configurations. The $t 10 c 12$-CLA isomer has been shown to be responsible for the reduction in milk fat synthesis in dairy cows and lactating sheep (Baumgard et al., 2002; Peterson et al., 2004; Lock et al., 
2006). However, the effects of minor CLA isomers on metabolism in animals are largely unknown. Therefore, because of the large number of CLA isomers contained in the CLA supplement, it is not known which CLA isomers were mainly responsible for the down-regulation of fatty acid transporters in the mammary gland of rats by the CLA supplement.

Whether down-regulation of fatty acid transporters in mammary tissue might also contribute to milk fat reduction by CLA in lactating cows is unknown. However, expression of fatty acid transporters in different tissues including mammary gland of cows has been reported (Ordovás et al., 2006; Bionaz and Loor, 2008a,b). Interestingly, expression of FAT/CD36 in mammary tissue of lactating cows largely increases during lactation, reaching a peak at about 6 wk postpartum, which corresponds to peak lactation in cows, and declines from then until weaning (Bionaz and Loor, 2008a). This pattern of FAT/CD36 expression during lactation is similar to the lactation course of daily yield of fatty acids with 16 and more carbon atoms, which originate from uptake from plasma, in the milk of dairy cows (Bionaz and Loor, 2008a); that is, daily yield of these fatty acids also peaks within a few weeks postpartum and markedly declines toward the end of lactation. This suggests that uptake of fatty acids from plasma plays an important role for milk fat synthesis during early and peak lactation in dairy cows. In contrast, daily yield of fatty acids synthesized de novo in cow milk predominates after 4 wk postpartum (Bionaz and Loor, 2008a), suggesting that fatty acid synthesis in mammary tissue plays a major role for milk fat synthesis during mid and late lactation in lactating cows. Therefore, it can be speculated that a potential impairment of fatty acid transport from plasma into mammary tissue by dietary CLA in lactating cows might significantly contribute to milk fat reduction only when CLA is administered during early lactation. However, the finding that CLA is less effective for milk fat reduction in early lactation than in mid or late lactation (Perfield et al., 2002) suggests that possible impairment of fatty acid uptake by CLA has only a minor effect on milk fat reduction in dairy cows. However, this assumption has to be proven in future studies.

The mechanism of the action of CLA on the expression of fatty acid transporters in the mammary gland cannot be resolved from the present study. It is known that regulation of fatty acid transporters includes transcriptional regulation through peroxisome proliferatoractivated receptors (PPAR)- $\alpha$ and $\gamma$ (Motojima et al., 1998; Frohnert et al., 1999). However, a central role of these transcription factors in the regulation of fatty acid transporter gene expression by CLA in the mammary gland is unlikely, because both PPAR $\alpha$ and
PPAR $\gamma$ show only negligible expression in the lactating mammary glands of rodents (Gimble et al., 1998; Rodriguez-Cruz et al., 2006). Other ways of regulating expression of these genes by CLA might be conceivable, because the promoter region of fatty acid transporter genes contains other regulatory elements including insulin responsive elements (Hui et al., 1998). Therefore, further studies are warranted to elucidate the mechanism by which CLA affect gene expression of fatty acid transporters.

In conclusion, our present findings in connection with recent observations (Baumgard et al., 2001, 2002; Ringseis et al., 2004) strongly indicate that reduced uptake of circulating NEFA released from white adipose tissue into the mammary gland could also contribute to the reduction of milk triacylglycerol concentrations by dietary CLA in rats. Whether this applies to other species such as cows and sheep has to be demonstrated in future studies. The mechanism through which CLA inhibits expression of fatty acid transporters deserves further studies.

\section{ACKNOWLEDGMENTS}

The authors thank D. Saal (Institut für Agrar-und Ernährungswissenschaften, Martin-Luther-Universität Halle-Wittenberg, Germany) for performance of the feeding experiment.

\section{REFERENCES}

Barber, M. C., A. J. Vallance, H. T. Kennedy, and M. T. Travers. 2003. Induction of transcripts derived from Promoter III of the acetylCoA carboxylase-alpha gene in mammary gland is associated with recruitment of SREBP-1 to a region of the proximal promoter defined by a DNase-I hypersensitive site. Biochem. J. T375:489501.

Baumgard, L. H., E. Matitashvili, B. A. Corl, D. A. Dwyer, and D. E. Bauman. 2002. T-10, cis-12 conjugated linoleic acid decreases lipogenic rates and expression of genes involved in milk lipid synthesis in dairy cows. J. Dairy Sci. 85:2155-2163.

Baumgard, L. H., J. K. Sangster, and D. E. Bauman. 2001. Milk fat synthesis in dairy cows is progressively reduced by increasing supplemental amounts of t-10, cis-12 conjugated linoleic acid (CLA). J. Nutr. 131:1764-1769.

Bionaz, M., and J. J. Loor. 2008a. Gene networks driving bovine milk fat synthesis during the lactation cycle. BMC Genomics 9:366.

Bionaz, M., and J. J. Loor. 2008b. ACSL1, AGPAT6, FABP3, LPIN1, and SLC27A6 are the most abundant isoforms in bovine mammary tissue and their expression is affected by stage of lactation. J. Nutr. 138:1019-1024.

Frohnert, B. I., T. Y. Hui, and D. A. Bernlohr. 1999. Identification of a functional peroxisome proliferator-responsive element in the murine fatty acid transport protein gene. J. Biol. Chem. 274:3970-3977.

Gimble, J. M., G. M. Pighetti, M. R. Lerner, X. Wu, S. A. Lightfoot, D. J. Brackett, K. Darcy, and A. B. Hollingsworth. 1998. Expression of peroxisome proliferator activated receptor mRNA in normal and tumorigenic rodent mammary glands. Biochem. Biophys. Res. Commun. 253:813-817.

Green, M. H., E. L. Dohner, and J. B. Green. 1981. Influence of dietary fat and cholesterol on milk lipids and on cholesterol metabolism in the rat. J. Nutr. 111:276-278. 
Harvatine, K. J., and D. E. Bauman. 2006. SREBP1 and thyroid hormone responsive spot 14 (S14) are involved in the regulation of bovine mammary lipid synthesis during diet-induced milk fat depression and treatment with CLA. J. Nutr. 136:2468-2474.

Hayashi, A. A., S. R. de Medeiros, M. H. Carvalho, and D. P. Lanna. 2007. Conjugated linoleic acid (CLA) effects on pups growth, milk composition and lipogenic enzymes in lactating rats. J. Dairy Res. $74: 160-166$.

Hui, T. Y., B. I. Frohnert, A. J. Smith, J. E. Schaffer, and D. A. Bernlohr. 1998. Characterization of the murine fatty acid transport protein gene and its insulin response sequence. J. Biol. Chem. 273:27420-27429.

Lock, A. L., B. M. Teles, J. W. Perfield II, D. E. Bauman, and L. A. Sinclair. 2006. A conjugated linoleic acid supplement containing t-10, cis-12 reduces milk fat synthesis in lactating sheep. J. Dairy Sci. 89:1525-1532.

Martin, J. C., S. Grégoire, M. H. Siess, M. Genty, J. M. Chardigny, O. Berdeaux, P. Juanéda, and J. L. Sébédio. 2000. Effects of conjugated linoleic acid isomers on lipid-metabolizing enzymes in male rats. Lipids 35:91-98.

Masters, N., M. A. McGuire, K. A. Beerman, N. Dasgupta, and M. K. McGuire. 2002. Maternal supplementation with CLA decreases milk fat in humans. Lipids 37:133-138.

Motojima, K., P. Passilly, J. M. Peters, F. J. Gonzalez, and N. Latruffe. 1998. Expression of putative fatty acid transporter genes are regulated by peroxisome proliferator-activated receptor $\alpha$ and $\gamma$ activators in a tissue- and inducer-specific manner. J. Biol. Chem. 273:16710-16714.

Ordovás, L., R. Roy, P. Zaragoza, and C. Rodellar. 2006. Structural and functional characterization of the bovine solute carrier family 27 member 1 (SLC27A1) gene. Cytogenet. Genome Res. 115:115122 .

Perfield, J. W. II, G. Bernal-Santos, T. R. Overton, and D. E. Bauman. 2002. Effects of dietary supplementation of rumen-protected conjugated linoleic acid in dairy cows during established lactation. J. Dairy Sci. 85:2609-2617.

Peterson, A. D., and B. R. Baumgardt. 1971. Food and energy intake of rats fed diets varying in energy concentration and density. J. Nutr. 101:1057-1067.

Peterson, D. G., E. A. Matitashvili, and D. E. Bauman. 2004. The inhibitory effect of trans-10, cis-12 CLA on lipid synthesis in bovine mammary epithelial cells involves reduced proteolytic activation of the transcription factor SREBP-1. J. Nutr. 134:2523-2527.

Ringseis, R., A. Muschick, and K. Eder. 2007. Dietary oxidized fat prevents ethanol-induced triacylglycerol accumulation and increases expression of PPAR $\alpha$ target genes in rat liver. J. Nutr. 137:77-83.

Ringseis, R., D. Saal, A. Müller, H. Steinhart, and K. Eder. 2004. Dietary conjugated linoleic acids lower the triacylglycerol concentration in the milk of lactating rats and impair the growth and increase the mortality of their suckling pups. J. Nutr. 134:3327-3334.

Rodriguez-Cruz, M., A. R. Tovar, B. Palacios-Gonzalez, M. Del Prado, and N. Torres. 2006. Synthesis of long-chain polyunsaturated fatty acids in lactating mammary gland: role of Delta5 and Delta6 desaturases, SREBP-1, PPARa, and PGC-1. J. Lipid Res. $47: 553-560$.

Ross, A. C., M. E. Davilla, and M. P. Cleary. 1985. Fatty acids and retinyl esters of rat milk. Effects of diet and duration of lactation. J. Nutr. 115:1488-1497.

Sainz, R. D., C. C. Calvert, and R. L. Baldwin. 1986. Relationships among dietary protein feed intake and changes in body composition of lactating rats. J. Nutr. 116:1529-1539.

Sampson, D. A., and G. R. Janson. 1984. Protein and energy nutrition during lactation. Annu. Rev. Nutr. 4:43-67.

Scow, R. O., S. S. Chernick, and T. R. Fleck. 1977. Lipoprotein lipase and uptake of triacylglycerol cholesterol and phosphatidyl choline from chylomicrons by mammary and adipose tissue of lactating rats in vivo. Biochim. Biophys. Acta 487:297-306.

Steinhart, H., R. Rickert, and K. Winkler. 2003. Identification and analysis of conjugated linoleic acid isomers (CLA). Eur. J. Med. Res. 8:370-372.

Terpstra, A. H. M., A. C. Beynen, H. Everts, S. Kocsis, M. B. Katan, and P. L. Zock. 2002. The decrease in body fat in mice fed conjugated linoleic acid is due to increases in energy expenditure and energy loss in the excreta. J. Nutr. 132:940-945.

Toomey, S., J. McMonagle, and H. M. Roche. 2006. Conjugated linoleic acid: A functional nutrient in the different pathophysiological components of the metabolic syndrome? Curr. Opin. Clin. Nutr. Metab. Care 9:740-747. 